\title{
NMDA Receptors in Accumbal D1 Neurons Influence Chronic Sugar Consumption and Relapse
}

\author{
Shoupeng Wei, ${ }^{1}$ Sarah Hertle, ${ }^{1}$ - Rainer Spanagel, ${ }^{2}$ and Ainhoa Bilbao ${ }^{1}$
}

https://doi.org/10.1523/ENEURO.0029-21.2021

${ }^{1}$ Behavioral Genetics Research Group, Institute of Psychopharmacology, Central Institute of Mental Health, Heidelberg University, Mannheim, 68159, Germany and ${ }^{2}$ Institute of Psychopharmacology, Central Institute of Mental Health, Heidelberg University, Mannheim, 68159, Germany

\begin{abstract}
Glutamatergic input via NMDA and AMPA receptors within the mesolimbic dopamine (DA) pathway plays a critical role in the development of addictive behavior and relapse toward drugs of abuse. Although well-established for drugs of abuse, it is not clear whether glutamate receptors within the mesolimbic system are involved in mediating chronic consumption and relapse following abstinence from a non-drug reward. Here, we evaluated the contribution of mesolimbic glutamate receptors in mediating chronic sugar consumption and the sugar-deprivation effect (SDE), which is used as a measure of relapse-like behavior following abstinence. We studied four inducible mutant mouse lines lacking the GluA1 or GluN1 subunit in either DA transporter (DAT) or D1R-expressing neurons in an automated monitoring system for free-choice sugar drinking in the home cage. Mice lacking either GluA1 or GluN1 in D1R-expressing neurons (GluA1 $1^{\text {D1CreERT2 }}$ or GluN1 ${ }^{D 1 C r e E R T 2}$ mice) have altered sugar consumption in both sexes, whereas GluA1 DATCreERT2 and GluN1 DATCreERT2 do not differ from their respective littermate controls. In terms of relapse-like behavior, female GluN1 ${ }^{D 1 C r e E R T 2}$ mice show a more pronounced SDE. Given that glutamate receptors within the mesolimbic system play a critical role in mediating relapse behavior of alcohol and other drugs of abuse, it is surprising that these receptors do not mediate the SDE, or in the case of female GluN1 ${ }^{D 1 C r e E R T 2}$ mice, show an opposing effect. We conclude that a relapse-like phenotype of sugar consumption differs from that of drugs of abuse on the molecular level, at least with respect to the contribution of mesolimbic glutamate receptors.
\end{abstract}

Key words: addictive phenotypes; glutamate receptors; mesolimbic system; mice; sugar; transgenic models

\section{Significance Statement}

Here, we provide evidence from various inducible and site-specific transgenic mouse models that glutamate receptors within the mesolimbic dopamine (DA) system do not play a critical role in relapse behavior in chronically sugar-drinking male and female mice. This differentiates a natural reward from drugs of abuse on the molecular level, as mesolimbic NMDA and AMPA receptors are essential for drug-induced neuroplasticity and subsequent relapse behavior.

\section{Introduction}

It is assumed that the problematic chronic use of sugar, similar to chronic consumption of drugs of abuse, can lead to an addictive-like phenotype. However, the concept of "sugar addiction" is controversial and only a few studies have attempted to determine the addictive

Received January 22, 2021; accepted April 16, 2021; First published April 27, 2021.

The authors declare no competing financial interests. properties of sugar using rigorous scientific criteria (Avena et al., 2009; Wiss et al., 2018).

These studies suggest that behavioral phenotypes associated with chronic consumption of drugs of abuse and sugar consumption are similar with respect to withdrawal responses, compulsive over-consumption, craving, and loss of control (Avena et al., 2009; Wiss et al., 2018). After

Author contributions: A.B. designed research; S.W. and S.H. performed research; S.W. and A.B. analyzed data; S.W., R.S., and A.B. wrote the paper. 
deprivation even relapse behavior can ensue. Thus, rats trained for $28 \mathrm{~d}$ to drink a sucrose solution and deprived for $14 \mathrm{~d}$ displayed a sugar-deprivation effect (SDE; Avena et al., 2005). In a more recent study (Wei et al., 2021), the addictive-like properties of sugar were systematically examined in male and female mice using established paradigms and models from the drug addiction field (SanchisSegura and Spanagel, 2006; Wei et al., 2021). In this study, female mice were more vulnerable to the addictivelike properties of sugar than male mice, showing higher long-term, excessive sugar drinking, and a more pronounced relapse-like sugar consumption as assessed by measuring the SDE (Wei et al., 2021). The deprivation effect is a measure of consumption during a relapse-like situation in the addiction field (Vengeliene et al., 2014; Spanagel, 2017).

Given the similarities of phenotypes for the chronic use of drugs of abuse and sugar, we speculated that there may also be similarities on the molecular level. In the addiction field, there is strong evidence that an interaction between the glutamatergic and mesolimbic dopamine (DA) systems is critical for mediating the reinforcing effects of drugs of abuse and consequently addictive behavior and relapse (Gass and Olive, 2008). In particular, glutamatergic synapses on DA neurons in the ventral tegmental area (VTA) and D1 receptor-expressing medium spiny neurons (MSNs) of the nucleus accumbens (NAc) both modulate the reinforcing properties of drugs of abuse and reward-dependent learning processes (Lüscher and Malenka, 2011; Lüscher, 2013; Scofield et al., 2016). In support of this, disruption of NMDA receptors in midbrain DA neurons abolishes enduring cocaineinduced plasticity in the NAc, thus reducing the incubation of craving and subsequent relapse behavior (Engblom et al., 2008; Mameli et al., 2009). Furthermore, using different mutant mouse lines that lack GluN1 and GluA1 receptor subunits in DA transporter (DAT) and D1R-expressing neurons, respectively, it was shown that GluN1 and GluA1 receptor subunits within these neuronal subpopulations mediate the alcohol-deprivation effect (ADE), which is a measure for relapse behavior (Eisenhardt et al., 2015a).

Some drug-induced neuroplastic changes within the mesolimbic system may also occur following consumption of natural rewards. For example, sucrose intake increases the phosphorylation and trafficking of accumbal AMPA receptor GluA1 subunits (Tukey et al., 2013) and alters the morphology of the MSNs (Klenowski et al., 2016).

This work was supported by the Federal Ministry of Education and Research (BMBF) Grant FKZ 01ZX1909-SysMedSUDs and by the Deutsche Forschungsgemeinschaft (DFG) Grant TRR265-Losing and Regaining Control over Drug Intake (Heinz et al., 2020).

Acknowledgements: We thank Dr. Rick Bernardi for English editing.

Correspondence should be addressed to Ainhoa Bilbao at ainhoa. bilbao@zi-mannheim.de.

https://doi.org/10.1523/ENEURO.0029-21.2021 Copyright (c) 2021 Wei et al.

This is an open-access article distributed under the terms of the Creative Commons Attribution 4.0 International license, which permits unrestricted use, distribution and reproduction in any medium provided that the original work is properly attributed.
In addition, other studies have shown that a natural reward experience activates VTA DA cells and alters AMPA and NMDA receptor distribution and function in the NAc similar to psychostimulants (Pitchers et al., 2012; Beloate et al., 2016). Therefore, mesolimbic glutamate receptors may, at least in part, be involved in mediating chronic sugar consumption and relapse following abstinence. Furthermore, there may be sex-dependent effects in sugar consumption and relapse, as female rats have increased levels of the AMPA receptor GluA1 and NMDA receptor NR1 subunits within the mesolimbic system after cocaine, methamphetamine or ethanol self-administration, relative to male rats (Devaud and Alele, 2004; Bechard et al., 2018; Pena-Bravo et al., 2019).

The aim of the present study was to systematically examine the involvement of AMPA and NMDA receptors within the mesolimbic system in mediating chronic longterm sugar consumption and the SDE in a sex-dependent manner. Here, we generated inducible mutant mice expressing GluN1 or GluA1 mutations under the control of the DAT (S/c6a3) or D1 (Drd1a) promoter following the previously described procedure (Mameli et al., 2009; Parkitna et al., 2009, 2010; Eisenhardt et al., 2015a). We focused on AMPA and NMDA receptors in D1-receptorcontaining MSNs, as several studies (Hikida et al., 2010; Lobo and Nestler, 2011; Calipari et al., 2016; SoaresCunha et al., 2016; Ma et al., 2018; Bilbao et al., 2020) suggest that this neuronal population is more involved in mediating the chronic effects of drug of abuse and natural rewards than D2-containing MSNs. Using a fully automated, highly precise home cage monitoring system (Eisenhardt et al., 2015b) for sugar drinking in mice, we systematically examined GluN1 DATCreERT2, GluA1 DATCreERT2, GluN1 D1CreERT2, and GluA1 D1CreERT2 male and female mice in a long-term free-choice sugar drinking procedure and studied the SDE following an abstinence phase.

\section{Materials and Methods}

\section{Animals}

We generated mutant mice expressing GluN1 or GluA1 mutations under control of the DAT (S/c6a3) or D1 (Drd1a) promoter following the previously described procedure (Mameli et al., 2009; Parkitna et al., 2009, 2010; Eisenhardt et al., 2015a). In short, GluN1 DATCreERT2

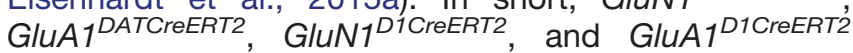
mice were generated by crossing mice with an inducible Cre-recombinase under the DAT- or D1-promoter with mice carrying floxed alleles for GluN1or GluA1. The $D A T C r e E R T 2$ and D1CreERT2 mice were generated by recombining a construct containing an improved Cre-recombinase fused to a modified ligand binding domain of the estrogen receptor (CreERT2) into a bacterial artificial chromosome containing the gene encoding DAT (S/c6a3) or D1 (Drd1a) by recombineering. GluN1 $1^{f / f t}$ and GluA1 $1^{f / f l}$ mice, having exons 11-18 of the Grin 1 or exon 11 of the Gria1 alleles, respectively, flanked with loxP sites were generated by gene targeting in embryonic stem cells (Zamanillo et al., 1999; Niewoehner et al., 2007). For induction of the mutation, mice were treated with $1 \mathrm{mg}$ of 
tamoxifen dissolved in neutral oil intraperitoneally twice a day for five consecutive days (Erdmann et al., 2007). Mice were treated with tamoxifen at an age of 8-10 weeks old and were allowed to recuperate for at least three weeks before experiments started. For genotyping of the DATCreERT2 and D1CreERT2 transgene, we used the primers GGC TGG TGT GTC CAT CCC TGA A and GGT CAA ATC CAC AAA GCC TGG CA. The GluN1 and GluA1 flox variants were genotyped using the primers GGA CAG CCC CTG GAA GCA AAA T and GGA CCA GGA CTT GCA GTC CAA AT for GluN1, and CAC TCA CAG CAA TGA AGC AGG AC and CTG CCT GGG TAA AGT GAC TTG G for GluA1. For all experiments, adult male and female

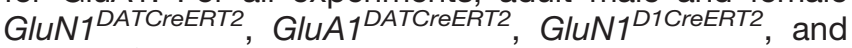
GluA1 ${ }^{D 1 C r e E R T 2}$ and their wild-type littermate mice from at least six consecutive backcrosses with C57BL/6N were used (8-10 weeks at the beginning of the experiments). As controls, floxed littermates not carrying the Cre-recombinase were used.

Mice were single-housed in standard hanging cages at $21 \pm 1^{\circ} \mathrm{C}$ and $50 \pm 5 \%$ relative humidity on a reversed 12/12 h light/dark cycle, with lights on at 7:30 P.M. The animals were provided with standard rodent food (Altromin Spezialfutter GmbH \& Co, LASQC diet Rod16-H. Composition: cereals, vegetable by-products, minerals, oils and fats, yeast; crude nutrients: $16.30 \%$ crude protein, $4.30 \%$ crude fat, $4.30 \%$ crude fiber, $7.00 \%$ crude ash), a bottle containing $5 \%(w / v)$ sugar solution during the long-term sugar paradigms (see below for details) and tap water ad libitum. All the experiments were performed in the dark cycle. All mice were handled on a daily basis before starting the experiments and were habituated to the behavioral testing environments. Procedures for this study complied with the regulations covering animal experimentation within the European Union (European Communities Council Directive 86/609/EEC) and Germany (Deutsches Tierschutzgesetz) and the experiment was approved by the German animal welfare authorities (Regierungspräsidium Karlsruhe).

\section{Home cage two-bottle free-choice sugar drinking and assessment of relapse-like drinking by means of the SDE}

For this experiment 360 mice were used in total, 49 GluN1DATCreERT2 (25 males and 24 females), 41 GluN1D1CreERT2 (21 males and 20 females), 53 GluA1 DATCREERT2 (26 males and 27 females),

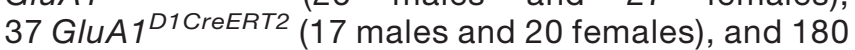
respective control littermates (90 males and $90 \mathrm{fe}-$ males) were used. Mice had continuous free-choice access to a bottle containing a sugar solution (sucrose $5 \% \mathrm{w} / \mathrm{v}$ ) and a bottle with tap water in the homecage for eight weeks. During the last $3 \mathrm{~d}$ of sugar exposure, sugar and water intake and locomotion were recorded using a drinkometer system (Eisenhardt et al., 2015a, b; Bilbao et al., 2019) and were used as baseline for comparison with the SDE. Mice were afterward deprived from sugar for 12-15d, during which they only had access to two bottles of tap water. After the deprivation period, the SDE was tested for $24 \mathrm{~h}$ by reintroducing the sugar bottle.

\section{Assessment of drinking patterns by a fully automated drinkometer device}

Sugar and water intake, preference over water and locomotor activity were measured during baseline and SDE measurements with a fully automated, highly precise monitoring system as described previously (INFRA-EMOTION; Eisenhardt et al., 2015a,b; Bilbao et al., 2019). Briefly, during recording, the standard lid of the mouse home cage was replaced with the drinkometer lid containing two holes for special drinkometer bottles with a curved bottleneck and different tips for water $(0.8 \mathrm{~mm}$ opening) and sugar (1.5 $\mathrm{mm}$ opening) solutions. The drinkometer system was configured to sample every 4 min, the amount (g) of sugar and water each mouse consumed. Sugar and water intake, preference over water and locomotor activity were calculated every $4 \mathrm{~h}$ to assess circadian drinking patterns and to obtain a temporal dissection of the SDE. The SDE in mice is usually shortlasting (Vengeliene et al., 2014) and therefore the first $4 \mathrm{~h}$ during the SDE provide the most valid measurement (Eisenhardt et al., 2015a).

Sugar $(\mathrm{g} / \mathrm{kg})$ and water $(\mathrm{ml})$ intake, sugar preference (\% of total fluid intake) and locomotor activity were calculated per day. During baseline and SDE measurements, sugar and water intake and locomotion were additionally calculated in 4-h time intervals. Baselines were calculated as the mean of the last $3 \mathrm{~d}$ of baseline recording.

\section{Statistics}

Statistical analyses were performed by one-way or twoway ANOVA with repeated measures and Newman-Keuls test for post hoc comparisons using Statistica 10 (StatSoft). All values are given as mean \pm SEM, and statistical significance was set at $p<0.05$.

The ANOVA model for the long-term free-choice home cage drinking and SDE contained the fixed effects of sugar deprivation (baseline and relapse), gene (wild-type and GluA1 or GluN1), and the interaction deprivation $\times$ gene.

\section{Results}

\section{Specific GluN1 receptor subunit gene inactivation}

After eight weeks of chronic, 24-h free-choice sugar exposure, male and female GluN1 $1^{D A T C r e E R T 2}$ mice did no differ from their wild-type littermates in the daily sugar intake (one-way ANOVA for Fig. $1 A: F_{(1,49)}=0.06, p=0.8$ and for Fig. 1G: $\left.F_{(1,47)}=2.7, p=0.1\right)$. Male GluN1 ${ }^{\text {DATCreERT2 }}$ mice displayed a decreased baseline locomotion compared with wild-types $\left(F_{(1,49)}=4.4, p<0.05\right.$; Fig. $\left.1 B\right)$, which was not the case for females, showing no difference between genotypes $\left(F_{(1,47)}=0.2, p=0.7\right.$; Fig. $\left.1 H\right)$.

A period of sugar deprivation significantly increased the sugar intake in all mutants, and the respective wild-type mice (Fig. 1C,I), indicative of a SDE (two-way ANOVA, deprivation effect for Fig. 1C: $F_{(11,539)}=62.3, p<0.0001$ and for Fig. 1/: $\left.F_{(11,517)}=72.8, p<0.0001\right)$. The dissection of 


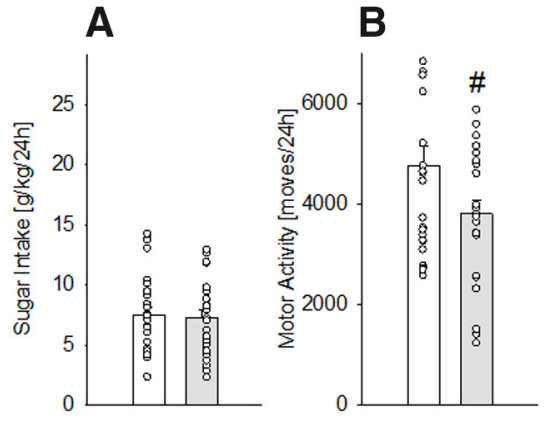

ए- Wild-type $(n=26)$
$-0-$ GluN1 ${ }_{\text {DATCRERT2 }}$ male $(n=25)$

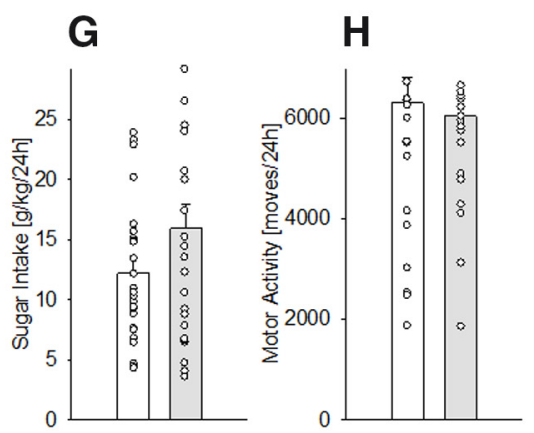

$-0-$ Wild-type $(\mathrm{n}=25)$
$-0-$ GluN1 ${ }_{\text {DATC ReERT2 }}$ female $(\mathrm{n}=24)$
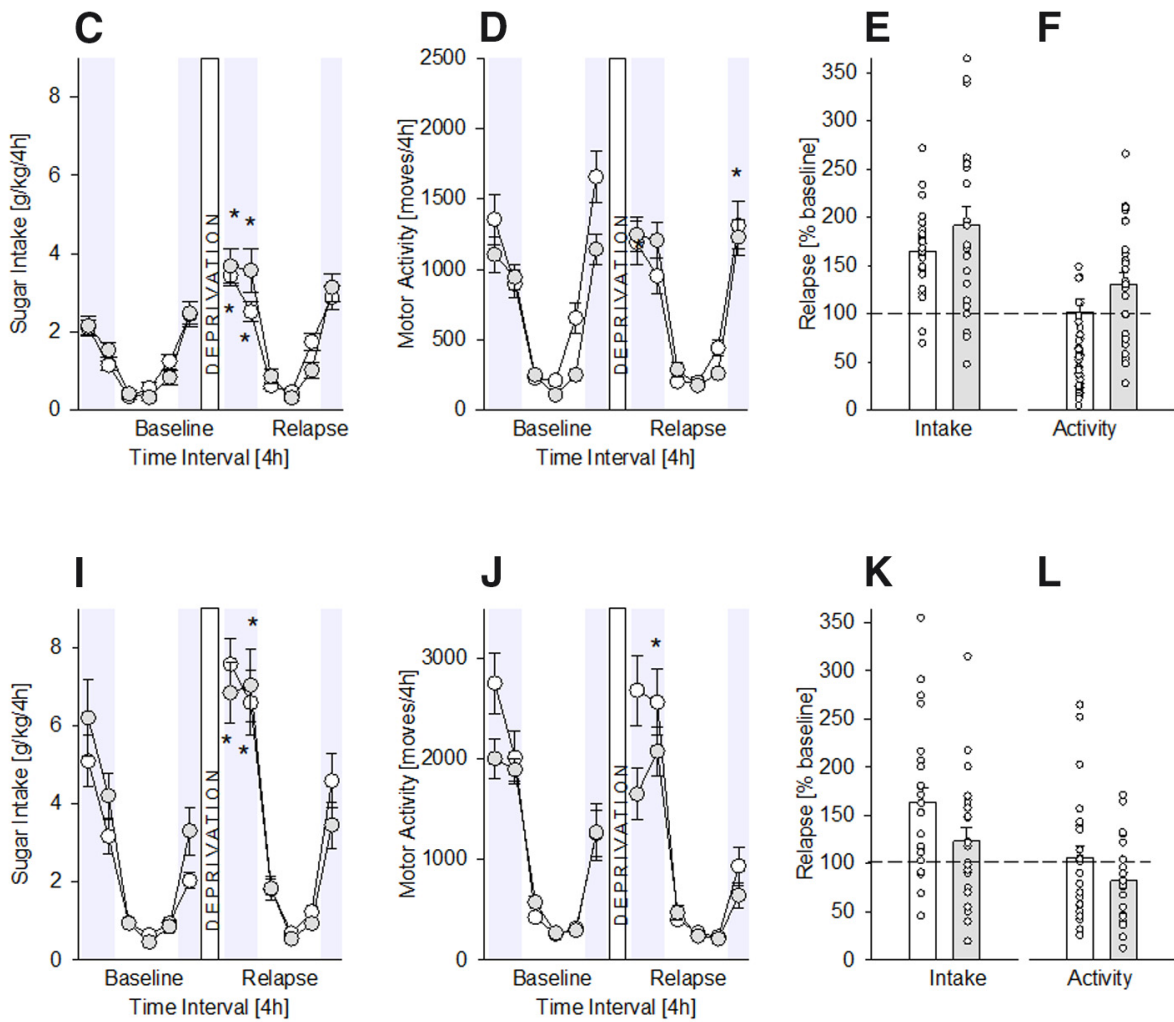

Figure 1. Characterization of chronic sugar drinking, SDE, and locomotor activity in male and female GluN1 $1^{D A T C}$ CERT2 mice. $\boldsymbol{A}$, G, Baseline sugar intake in $\mathrm{g} / \mathrm{kg} / \mathrm{d}$ after free-choice access to a bottle containing a sugar solution (5\% w/v) and a bottle with tap water in the homecage for eight weeks in wild-type male $(n=26)$, female $(n=25)$, and GluN1 DATCreERT2 male $(n=25)$ and female $(n=24)$ mice. $\boldsymbol{B}, \boldsymbol{H}$, Baseline locomotor activity after eight weeks of free-choice sugar drinking. $\boldsymbol{C}, \boldsymbol{I}$, Diurnal drinking pattern during baseline sucrose consumption and during the SDE. $\boldsymbol{D}, \boldsymbol{J}$, Diurnal activity pattern during baseline sucrose consumption and during the SDE. $\boldsymbol{E}, \boldsymbol{K}$, Relapse behavior measured in \% change from baseline during the first $4 \mathrm{~h}$ of the SDE. $\boldsymbol{F}, \boldsymbol{L}$, Relative change in locomotor activity during the first $4 \mathrm{~h}$ of the SDE in relation to baseline activity; ${ }^{*}$ indicates significant changes $(p<0.001)$ in sucrose consumption or activity during the SDE when compared with baseline; \# indicates significant $(p<0.05)$ genotype differences.

the baseline and SDE drinking into 4-h time interval points showed the typical diurnal pattern of intake, characterized by higher drinking during the dark, active phase, and lower drinking during the light, inactive phase of the day. Specifically, during the SDE (i.e., relapse), sugar intake was strongly pronounced during the first 4-8 $\mathrm{h}$ of re-exposure and lasted not longer than $24 \mathrm{~h}$ in all genotypes (twoway ANOVA, gene effect for Fig. $1 C: F_{(1,49)}=1.3, p=0.7$ and for Fig. 1/: $F_{(1,47)}=0.07, p=0.8$, Neuman-Keuls post hoc $p<0.001$ ). A similar diurnal pattern was observed in the locomotor activity (Fig. $1 D, J$ ) during baseline and SDE. A period of sugar deprivation also influenced locomotor activity (deprivation effect for Fig. 1D: $F_{(11,539)}=$ 58.5, $p<0.0001$ and for Fig. 1J: $F_{(11,517)}=66.2$, $p<0.0001$ ), by increasing locomotion in mutant males and in wild-type females at the end and the beginning of the SDE, respectively, a phenomenon not related to GluN1 mutations (gene effect for Fig. 1D: $F_{(1,49)}=1.6$, $p=0.2$ and for Fig. $1 \mathrm{~J}$ : $F_{(1,47)}=2.3, p=0.1$, Neuman-Keuls post hoc $p<0.001$ ). Supporting these results, the percentage of relapse over baseline during the first $4 \mathrm{~h}$ of sugar re-exposure for intake and locomotion (Fig. 1E,K, F, $L$ ) indicated similar SDE magnitude in mutant and control mice (one-way ANOVA for Fig. $1 E: F_{(1,49)}=1.7, p=0.2$ and for Fig. $1 K: F_{(1,47)}=3.8, p=0.06$; for Fig. $1 F: F_{(1,49)}=2.5$, $p=0.1$ and for Fig. $\left.1 L: F_{(1,47)}=2.5, p=0.1\right)$.

In contrast to the DAT-containing neurons, GluN1 mutation onto D1-containing neurons (GluN1 D1CreERT2 mice) had an effect on chronic sugar drinking. As depicted in Figure 2, male (Fig. 2A) and female (Fig. 2G) GluN1 ${ }^{D 1 C r E E R T 2}$ mice showed a significant decrease in the total, 24-h free-choice sugar drinking (one-way ANOVA for Fig. $2 A: F_{(1,38)}=4.5, p<0.05$ and for Fig. $\left.2 G: F_{(1,37)}=5.9, p<0.05\right)$. No differences were found between genotypes in locomotor activity at baseline (Fig. 2B: $F_{(1,38)}=1.3, p=0.3$ and Fig. $2 H: F_{(1,37)}=$ $0.001, p=1)$.

Furthermore (and in contrast to the DAT-containing neurons), GluN1 mutation onto D1-containing neurons (GluN1 ${ }^{\text {D1CreERT2 }}$ mice) had an impact on the SDE. Thus, although a period of sugar deprivation significantly increased the sugar intake in all mice (Fig. $2 \mathrm{C}, \mathrm{l})$, indicating a SDE (two way ANOVA, deprivation effect for Fig. 2C: $F_{(11,418)}=63.5, p<0.0001$ and for Fig. $21: F_{(11,407)}=66.6$, $p<0.0001$ ), statistical analysis also showed a gene $\times$ deprivation interaction effect (for Fig. 2C: $F_{(11,418)}=4.4$, $p<0.0001$ and for Fig. 2l: $F_{(11,407)}=1.9, p<0.05$, Neuman-Keuls post hoc $p<0.05)$. Again, the SDE was 


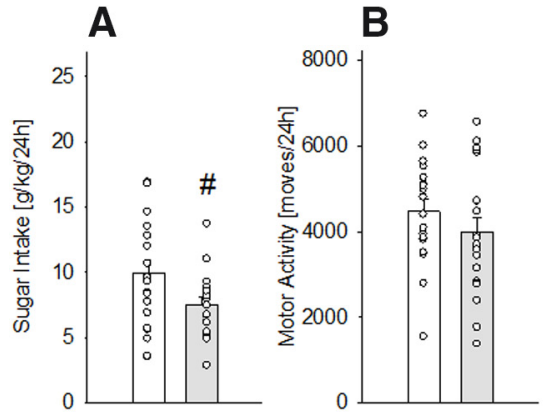

- - - Wild-type $(\mathrm{n}=19)$

$\square$ - GluN1 ${ }^{\text {DCREERT2 }}$ male $(n=21)$

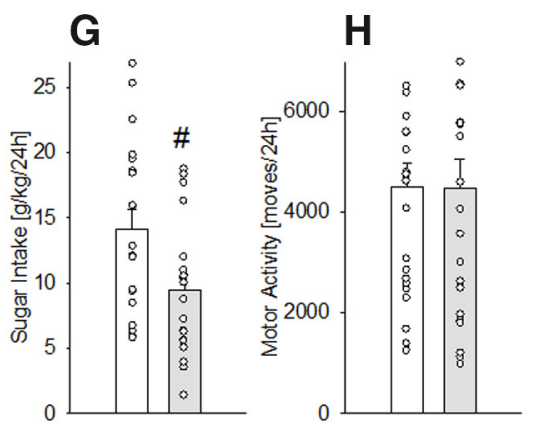

$-0-$ Wild-type $(n=20)$
$-0-$ GluN1 ${ }^{\text {DicreERT2 }}$ female $(n=19$
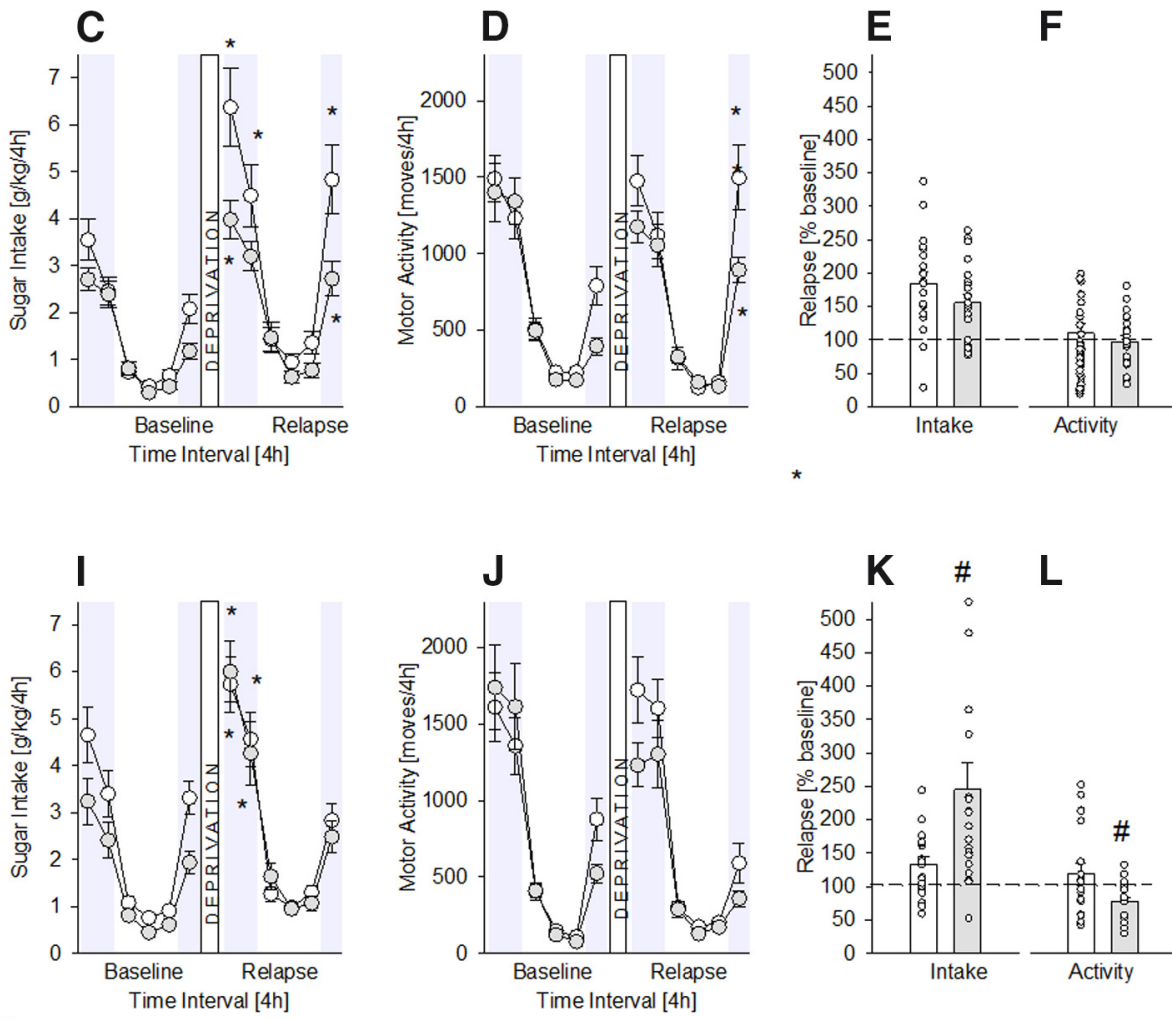

Figure 2. Characterization of chronic sugar drinking, SDE, and locomotor activity in male and female GluN1 ${ }^{D 1 C r e E R T 2}$ mice. A, G, Baseline sugar intake in $\mathrm{g} / \mathrm{kg} / \mathrm{d}$ after free-choice access to a bottle containing a sugar solution $(5 \% \mathrm{w} / \mathrm{v})$ solution and a bottle with tap water in the homecage for eight weeks in wild-type male $(n=19)$, female $(n=20)$, and GluN1 ${ }^{\text {DCreERT2 }}$ male $(n=21)$ and female $(n=19)$ mice. $\boldsymbol{B}, \boldsymbol{H}$, Baseline locomotor activity after eight weeks of free-choice sugar drinking. $\boldsymbol{C}, \boldsymbol{I}$, Diurnal drinking pattern during baseline sucrose consumption and during the SDE. $\boldsymbol{D}, \boldsymbol{J}$, Diurnal activity pattern during baseline sucrose consumption and during the SDE. $\boldsymbol{E}, \boldsymbol{K}$, Relapse behavior measured in \% change from baseline during the first $4 \mathrm{~h}$ of the SDE. $\boldsymbol{F}, \boldsymbol{L}$, Relative change in locomotor activity during the first $4 \mathrm{~h}$ of the SDE in relation to baseline activity; * indicates significant changes $(p<0.05)$ in sucrose consumption or activity during the SDE when compared with baseline; \# indicates significant $(p<0.05$ or $p<0.01$ for $\boldsymbol{A}$, $\mathbf{G}, \boldsymbol{L}, \boldsymbol{K}$, respectively) genotype differences.

strongly pronounced during the first $4-8 \mathrm{~h}$ of re-exposure and lasted not longer than $24 \mathrm{~h}$ in all mice. Locomotor activity (Fig. $1 D, J)$ was also influenced by the SDE, with males showing increased activity at the end of the SDE period (deprivation effect for Fig. 1D: $F_{(11,418)}=55.3$, $p<0.0001$, Neuman-Keuls post hoc $p<0.05$ and for Fig. $\left.1 \mathrm{~J}: F_{(11,407)}=54.2, p<0.0001\right)$. When calculating the percentage of relapse over baseline during the first $4 \mathrm{~h}$ of sugar re-exposure for intake and locomotion, male GluN1 ${ }^{\text {D1CreERT2 }}$ mice did not differ from their wild-type littermates (one-way ANOVA for Fig. $2 E: F_{(1,37)}=1.9, p=0.2$ and for Fig. $\left.2 F: F_{(1,37)}=0.3, p=0.6\right)$. However, in females, the SDE magnitude was higher for the intake (Fig. $2 K$ : $F_{(1,37)}=8, p<0.01$ ) and lower for the locomotion (Fig. $2 L$ : $\left.F_{(1,37)}=6.2, p<0.05\right)$.

\section{Specific GluA1 receptor subunit gene inactivation}

Deletion of the AMPA receptor GluA1 subunit onto DAT-containing neurons did not have any effect on chronic sugar drinking, as the phenotypes displayed by both male (Fig. $3 A, B$ ) and female (Fig. 3G,H) GluA1DATCreERT2 mice did not differ from their respective wild-type littermates after eight weeks of chronic, 24-h free-choice sugar exposure. As shown in Figure 3 , daily sugar consumption (one-way ANOVA for Fig. $3 A: F_{(1,50)}=0.1, p=0.7$ and for Fig. $3 G: F_{(1,50)}=$ 1.3, $p=0.3$ ) as well as locomotor activity (Fig. $3 B$ : $F_{(1,50)}=1.5, p=0.2$ and Fig. $\left.3 H: F_{(1,50)}=0.1, p=0.7\right)$ remained unaltered in the mutants.

Deletion of the AMPA receptor GluA1 subunit onto DAT-containing neurons did not have a role in relapse to sugar, as measured by the SDE (Fig. $3 C-F, I-L$ ). During baseline and SDE, the intake during 4-h intervals resembled the one already observed with GluN1 mutations. That is, all mice showed the typical diurnal pattern of consumption, and a strongly pronounced sugar intake during the first 4-8 h of re-exposure which lasted not longer than $24 \mathrm{~h}$. Statistical analysis showed a deprivation effect for male (Fig. 3C: $F_{(11,550)}=60.7, p<0.0001$, Neuman-Keuls post hoc $p<0.01$ ) and female (Fig. 3l: $F_{(11,550)}=85.2$, $p<0.0001$, Neuman-Keuls post hoc $p<0.01$ ), which was not GluA1 dependent (gene effect for Fig. $3 C: F_{(1,50)}=2.4$, $p=0.1$ and for Fig. 3/: $\left.F_{(1,50)}=1, p=0.3\right)$. Locomotor activity did not differ between baseline and SDE (Fig. 3D,J) for mutants and controls (two-way ANOVA for Fig. 3D: 


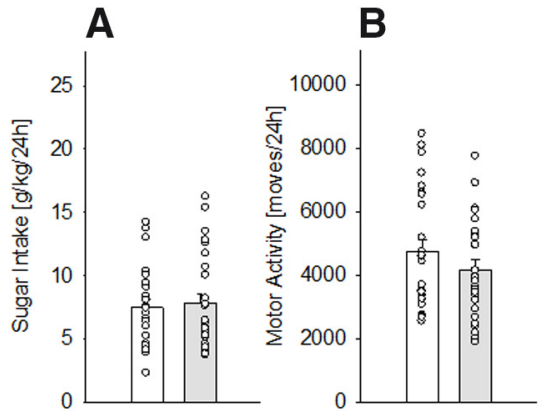

ऍ- Wild-type $(n=26)$
$-0-$ GluA1 $_{\text {DATCREERT2 }}$ male $(n=26)$
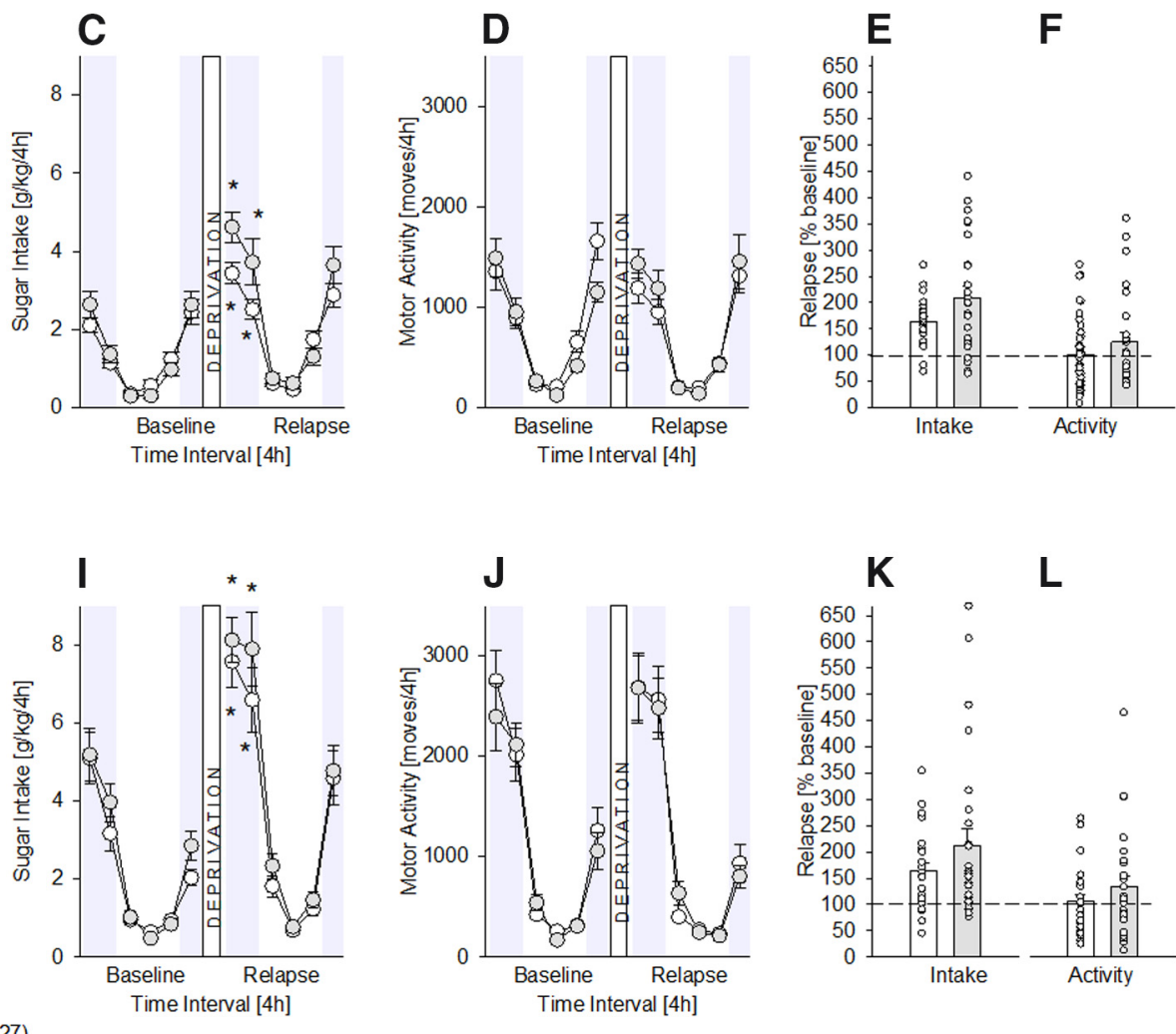
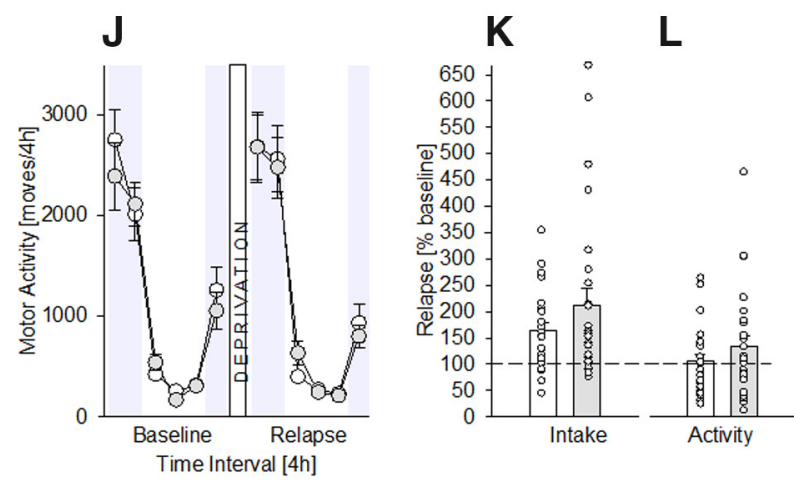

Figure 3. Characterization of chronic sugar drinking, SDE, and locomotor activity in male and female GluA1 DATCreERT2 mice. A, G, Baseline sugar intake in $\mathrm{g} / \mathrm{kg} / \mathrm{d}$ after free-choice access to a bottle containing a sugar solution $(5 \% \mathrm{w} / \mathrm{v})$ solution and a bottle with tap water in the homecage for eight weeks in wild-type male $(n=26)$, female $(n=25)$, and GluA1 DATCreERT2 male $(n=26)$ and female $(n=27)$ mice. $\boldsymbol{B}, \boldsymbol{H}$, Baseline locomotor activity after eight weeks of free-choice sugar drinking. $\boldsymbol{C}$, $\boldsymbol{I}$, Diurnal drinking pattern during baseline sucrose consumption and during the SDE. $\boldsymbol{D}, \boldsymbol{J}$, Diurnal activity pattern during baseline sucrose consumption and during the SDE. $\boldsymbol{E}, \boldsymbol{K}$, Relapse behavior measured in \% change from baseline during the first $4 \mathrm{~h}$ of the SDE. $\boldsymbol{F}, \boldsymbol{L}$, Relative change in locomotor activity during the first $4 \mathrm{~h}$ of the SDE in relation to baseline activity; ${ }^{*}$ indicates significant changes $(p<0.01)$ in sucrose consumption or activity during the SDE when compared with baseline.

$F_{(1,50)}=0.1, p=0.7$ and for Fig. 3J: $\left.F_{(1,50)}=0.1, p=0.8\right)$, although statistical analysis showed a deprivation effect (Fig. 3D: $F_{(11,550)}=42, p<0.001$ and Fig. $3 \mathrm{~J}: F_{(11,550)}=70$, $p<0.001$ ). In line with these results, the percentage of relapse over baseline during the first $4 \mathrm{~h}$ of sugar re-exposure for intake and locomotion, did not differ in male (Fig. $3 E: F_{(1,50)}=3.9, p=0.06$ and Fig. $\left.3 F: F_{(1,50)}=1.1, p=0.3\right)$ or female (Fig. $3 K: F_{(1,50)}=0.7, p=0.4$ and Fig. $3 L: F_{(1,50)}=$ $0.7, p=0.4)$ GluA1 DATCreERT2 mice from their wild-type littermates.

As observed with the GluN1 mutant mice, GluA1 mutation onto D1-containing neurons (in contrast to the DATcontaining neurons), had an effect on chronic sugar drinking behavior (Fig. 4). That is, regardless of the sex, GluA1 ${ }^{\text {D1CreERT2 }}$ mice showed a significant increase in the total, 24-h free-choice sugar drinking (one-way ANOVA, Fig. $4 A: F_{(1,35)}=4.3, p<0.05$ and Fig. $4 G: F_{(1,38)}=17.1$, $p<0.001)$. Regarding locomotor activity, it did not change in male mutants (Fig. $4 B: F_{(1,35)}=0.9, p=0.3$ ), but it was significantly increased in female GluA1 ${ }^{\text {D1CreERT2 }}$ mice (Fig. $4 H$ : $F_{(1,38)}=6.9, p<0.05$ ).

Similar to the DAT-containing mutant mice, GluA1 mutation onto D1-containing neurons did not influence the SDE (Fig. 4), and all mice showed increased sugar intake after deprivation during the first 4-8 $\mathrm{h}$ of re-exposure (twoway ANOVA, deprivation effect for Fig. $4 C: F_{(11,550)}=60.7$, $p<0.001$ and Fig. 4l: $F_{(11,418)}=73, p<0.001$, NeumanKeuls post hoc $p<0.05)$. However, locomotor activity was not only influenced by a sugar deprivation period (Fig. 4D: $F_{(11,550)}=55, p<0.001$ and Fig. 4J: $F_{(11,418)}=55.6$, $p<0.001$, Neuman-Keuls post hoc $p<0.05$ ), but also by the GluA1 receptor (two-way ANOVA, gene effect: Fig. 4D: $F_{(1,50)}=4.2, p<0.05$ and Fig. 4J: $F_{(1,38)}=12.3, p<0.01$; gene $\times$ deprivation interaction effect: Fig. $4 D: F_{(11,550)}=1.8$, $p<0.001$ and Fig. 4 J: $\left.F_{(11,418)}=4.6, p<0.001\right)$ as only the male and female mutants showed an increased locomotor activity at the end of the SDE period. Calculating the percentage of relapse during the first $4 \mathrm{~h}$ of sugar re-exposure for intake and locomotion similar SDE magnitudes were found in both males (Fig. $4 E: F_{(1,50)}=0.006, p=1$ and Fig. $4 F: F_{(1,50)}=$ $0.06, p=0.08$ ) and females (Fig. $4 K: F_{(1,38)}=2, p=0.2$ and Fig. 4L: $\left.F_{(1,38)}=0.005, p=0.9\right)$ compared with their respective wild-type littermates.

\section{Discussion}

Here, we report on three findings in different inducible mouse mutant lines lacking either GluN1 or GluA1 


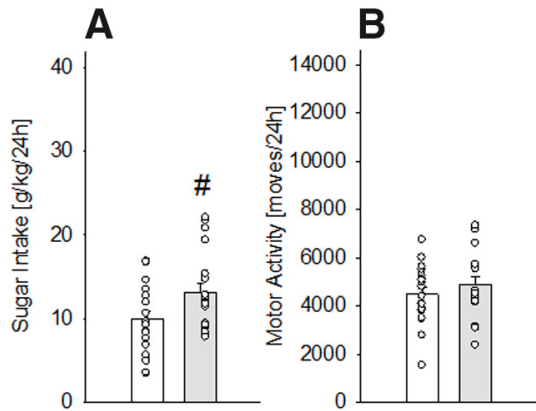

—- Wild-type $(n=19)$

$$
\begin{aligned}
& \text { - Wild-type }(n=19) \\
& -0-\text { GluA1 }{ }_{\text {DCreerT2 }} \text { male }(n=18)
\end{aligned}
$$

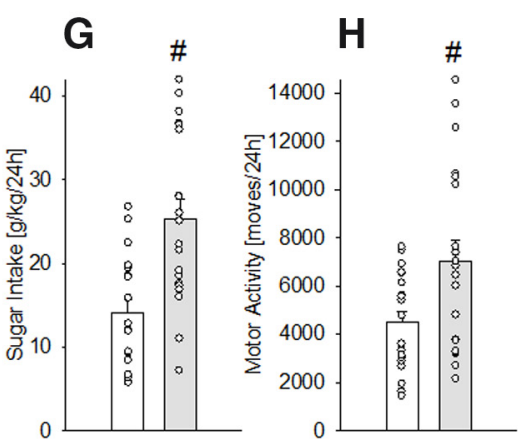

$-0-$ Wild-type $(n=20)$
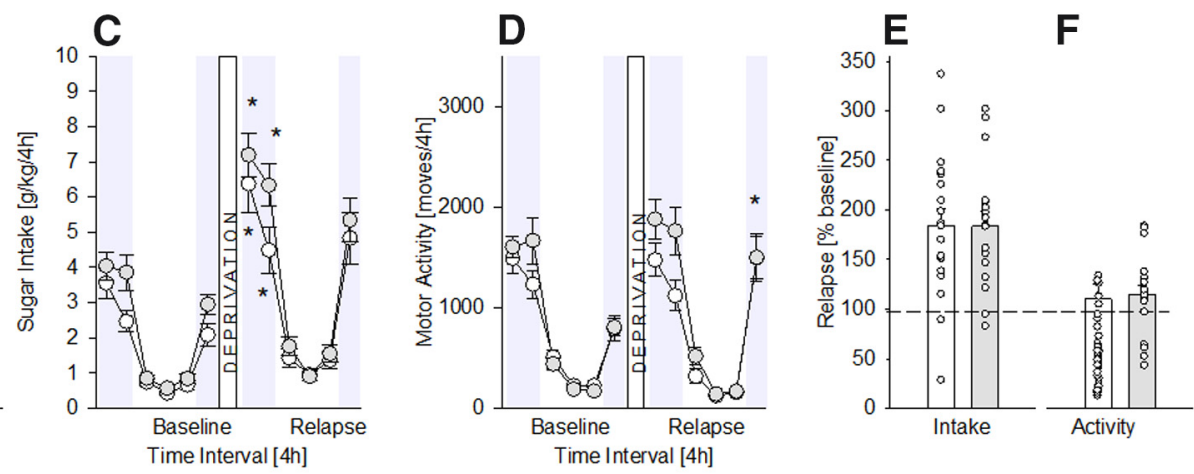
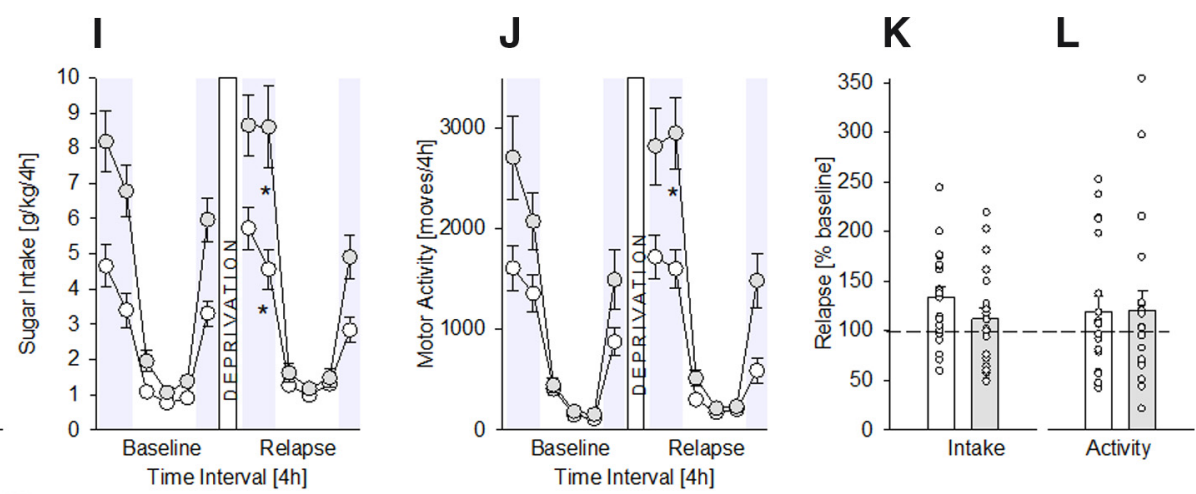

Figure 4. Characterization of chronic sugar drinking, SDE, and locomotor activity in male and female GluA1 $1^{D 1 C r e E R T 2}$ mice. A, G, Baseline sugar intake in $\mathrm{g} / \mathrm{kg} / \mathrm{d}$ after free-choice access to a bottle containing a sugar solution $(5 \% \mathrm{w} / \mathrm{v})$ solution and a bottle with

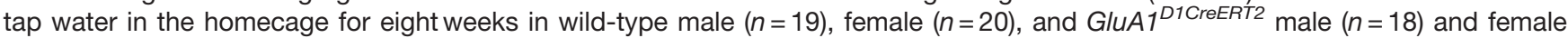
$(n=20)$ mice. $\boldsymbol{B}, \boldsymbol{H}$, Baseline locomotor activity after eight weeks of free-choice sugar drinking. $\boldsymbol{C}, \boldsymbol{I}$, Diurnal drinking pattern during baseline sucrose consumption and during the SDE. $\boldsymbol{D}, \boldsymbol{J}$, Diurnal activity pattern during baseline sucrose consumption and during the SDE. $\boldsymbol{E}, \boldsymbol{K}$, Relapse behavior measured in \% change from baseline during the first $4 \mathrm{~h}$ of the SDE. $\boldsymbol{F}, \boldsymbol{L}$, Relative change in locomotor activity during the first $4 \mathrm{~h}$ of the SDE in relation to baseline activity; ${ }^{*}$ indicates significant changes $(p<0.05)$ in sucrose consumption or activity during the SDE when compared with baseline; \# indicates significant $(p<0.05)$ genotype differences.

receptor subunits in DAT or D1-containing neurons in a chronic free-choice sugar consumption paradigm and the SDE model. First, long-term sugar intake is modulated by AMPA and NMDA receptors in D1-containing neurons in an opposing manner. The specific deletion of the GluA1 subunit, which yields non-functional AMPA receptors in primarily D1-containing MSNs, increases excessive sugar drinking in male and female mice, whereas mice with inducible GluN1 receptor subunit deletion in D1-expressing neurons show significantly reduced chronic sugar intake. Second, neither AMPA nor NMDA receptors in DA neurons influence the development and maintenance of sugar consumption. Third, female GluN1 $1^{D 1 C r e E R T 2}$ mice show a more pronounced relapse-like behavior in the SDE model.

The four genetic mouse models used here have some advantages over other approaches for gene targeting, allowing a more precise demonstration of the functional role regarding the gene of interest. First, these mutant models have high specificity of the deletion of GluN1 or GluA1 in DAT-expressing or D1-expressing neurons, as shown by previous co-localization studies (Engblom et al., 2008; Eisenhardt et al., 2015a). Cre- expression patterns fit with that described for DAT with strong expression in the VTA and for D1Rs with strong expression in the NAc and dorsal striatum. From previous studies (Engblom et al., 2008; Eisenhardt et al., 2015a), we conclude that we primarily have an ablation of individual glutamate receptor subunits within the mesolimbic DA system in our four mutant mouse lines. Second, the use of a temporally controlled gene deletion (induced by tamoxifen injections) circumvents potential developmental compensatory mechanisms, which may offset the loss of the gene and consequently mask its functional role.

As previously reported (Wei et al., 2021), mice show a typical diurnal pattern of sugar consumption. In all four mouse lines, such a pattern is maintained, and females showed consistently higher intake of a sugar solution relative to male mice. Long-term sugar intake was significantly more pronounced in GluA1 $1^{\text {D1CreERT2 }}$ male and female mice, suggesting that functional AMPA receptors onto D1-containing neurons play a role in the regulation of excessive sugar consumption. Our finding largely agrees with a previous report that studied the regulation of AMPA receptors on NAc synapses by sucrose intake. Tukey et 
al. (2013) showed that repeated daily ingestion of a sucrose solution potentiated accumbal synapses through incorporation of calcium permeable AMPA receptors. In contrast, deletion of functional NMDA receptors on D1-expressing neurons reduced excessive sugar intake in both sexes. This finding is consistent with the few studies to date that have addressed the role of NMDA receptors in food or sugar binging, which have reported a reduction after systemic administration of the NMDA receptor antagonist memantine (Bisaga et al., 2008; Popik et al., 2011). A reduction of binge eating following memantine treatment was also seen in a human study (Brennan et al., 2008). These results and the fact that our GluN1 DATCreERT2 and GluN1 ${ }^{D 1 C r e E R T 2}$ mutant mice showed no change in sugar binging suggest that non-mesolimbic brain regions may also contribute to sugar binging.

In terms of relapse-like behavior, we tested the four mutant mouse lines in the SDE model and found that neither AMPA nor NMDA receptors in DA neurons influenced augmented sugar consumption following a deprivation period. However, female GluN1 ${ }^{D 1 C r e E R T 2}$ mutant mice showed a more pronounced SDE. In contrast, relapse behavior to drugs of abuse is strongly under the control of mesolimbic glutamate receptors, especially the ADE, like the SDE a measure of relapse-like behavior (Vengeliene et al., 2014). All four mouse mutant lines tested here were also tested in a previous study for alcohol relapse behavior. All mutant mice showed a significantly reduced ADE, results supported by intra-VTA and intra-accumbal pharmacological blockade of AMPA and NMDA receptors (Eisenhardt et al., 2015a). Similarly, the AMPA antagonist GYKI 54266 completely abolished the ADE in rats (Sanchis-Segura et al., 2006) and a variety of NMDA receptor antagonists dose-dependently inhibited the ADE in rats (Hölter et al., 1996, 2000; Vengeliene et al., 2005; Kolik et al., 2017). For other drugs of abuse there are also consistent findings demonstrating that mesolimbic AMPA and NMDA receptors are critical for relapse behavior. Accumbal blockade of AMPA or NMDA receptors by various antagonists blocks relapse behavior for cocaine, heroin, and nicotine (Bäckström and Hyytiä, 2007; LaLumiere and Kalivas, 2008; Gipson et al., 2013; Doyle et al., 2014) and deletion of NMDA receptors in D1-containing neurons reduces the incubation of cocaine-seeking and relapse (Mameli et al., 2009). In conclusion, pharmacological inhibition or genetic inactivation of acccumbal NMDA receptors reduces relapse to drugs of abuse/alcohol, whereas GluN1 $1^{D 1 C r e E R T 2}$ female mutant mice exhibit an augmented SDE.

In summary, a previous study demonstrated the occurrence of an addictive-like phenotype for sugar in male and female mice similar to that of drugs of abuse (Wei et al., 2021). Here, we show that mesolimbic AMPA and NMDA receptor do not play a critical role in relapse to sugar consumption. These findings differentiate a natural reward from drugs of abuse on the molecular level, as mesolimbic NMDA and AMPA receptors are essential for drug-induced neuroplasticity and subsequent relapse behavior.

\section{References}

Avena NM, Long KA, Hoebel BG (2005) Sugar-dependent rats show enhanced responding for sugar after abstinence: evidence of a sugar deprivation effect. Physiol Behav 84:359-362.

Avena NM, Rada P, Hoebel BG (2009) Sugar and fat bingeing have notable differences in addictive-like behavior. J Nutr 139:623-628.

Bäckström P, Hyytiä P (2007) Involvement of AMPA/kainate, NMDA, and mGlu5 receptors in the nucleus accumbens core in cue-induced reinstatement of cocaine seeking in rats. Psychopharmacology (Berl) 192:571-580.

Bechard AR, Hamor PU, Schwendt M, Knackstedt LA (2018) The effects of ceftriaxone on cue-primed reinstatement of cocaineseeking in male and female rats: estrous cycle effects on behavior and protein expression in the nucleus accumbens. Psychopharmacology (Berl)235:837-848.

Beloate LN, Omrani A, Adan RA, Webb IC, Coolen LM (2016) Ventral tegmental area dopamine cell activation during male rat sexual behavior regulates neuroplasticity and d-amphetamine cross-sensitization following sex abstinence. J Neurosci 36:9949-9961.

Bilbao A, Leixner S, Wei S, Cantacorps L, Valverde O, Spanagel R (2019) Reduced sensitivity to ethanol and excessive drinking in a mouse model of neuropathic pain. Addict Biol 24:1008-1018.

Bilbao A, Neuhofer D, Sepers M, Wei SP, Eisenhardt M, Hertle S, Lassalle O, Ramos-Uriarte A, Puente N, Lerner R, Thomazeau A, Grandes P, Lutz B, Manzoni OJ, Spanagel R (2020) Endocannabinoid LTD in accumbal D1 neurons mediates rewardseeking behavior. iScience 23:100951.

Bisaga A, Danysz W, Foltin RW (2008) Antagonism of glutamatergic NMDA and mGluR5 receptors decreases consumption of food in baboon model of binge-eating disorder. Eur Neuropsychopharmacol 18:794-802.

Brennan BP, Roberts JL, Fogarty KV, Reynolds KA, Jonas JM, Hudson JI (2008) Memantine in the treatment of binge eating disorder: an open-label, prospective trial. Int J Eat Disord 41:520526.

Calipari ES, Bagot RC, Purushothaman I, Davidson TJ, Yorgason JT, Peña CJ, Walker DM, Pirpinias ST, Guise KG, Ramakrishnan C, Deisseroth K, Nestler EJ (2016) In vivo imaging identifies temporal signature of D1 and D2 medium spiny neurons in cocaine reward. Proc Natl Acad Sci USA 113:2726-2731.

Devaud LL, Alele P (2004) Differential effects of chronic ethanol administration and withdrawal on gamma-aminobutyric acid type $A$ and NMDA receptor subunit proteins in male and female rat brain. Alcohol Clin Exp Res 28:957-965.

Doyle SE, Ramôa C, Garber G, Newman J, Toor Z, Lynch WJ (2014) A shift in the role of glutamatergic signaling in the nucleus accumbens core with the development of an addicted phenotype. Biol Psychiatry 76:810-815.

Eisenhardt M, Leixner S, Luján R, Spanagel R, Bilbao A (2015a) Glutamate receptors within the mesolimbic dopamine system mediate alcohol relapse behavior. J Neurosci 35:15523-15538.

Eisenhardt M, Leixner S, Spanagel R, Bilbao A (2015b) Quantification of alcohol drinking patterns in mice. Addict Biol 20:1001-1011.

Engblom D, Bilbao A, Sanchis-Segura C, Dahan L, Perreau-Lenz S, Balland B, Parkitna JR, Luján R, Halbout B, Mameli M, Parlato R, Sprengel R, Lüscher C, Schütz G, Spanagel R (2008) Glutamate receptors on dopamine neurons control the persistence of cocaine seeking. Neuron 59:497-508.

Erdmann G, Schütz G, Berger S (2007) Inducible gene inactivation in neurons of the adult mouse forebrain. BMC Neurosci 8:63.

Gass JT, Olive MF (2008) Glutamatergic substrates of drug addiction and alcoholism. Biochem Pharmacol 75:218-265.

Gipson CD, Reissner KJ, Kupchik YM, Smith AC, Stankeviciute N, Hensley-Simon ME, Kalivas PW (2013) Reinstatement of nicotine seeking is mediated by glutamatergic plasticity. Proc Natl Acad Sci USA 110:9124-9129.

Heinz A, Kiefer F, Smolka MN, Endrass T, Beste C, Beck A, Liu S, Genauck A, Romund L, Banaschewski T, Bermpohl F, Deserno L, Dolan RJ, Durstewitz D, Ebner-Priemer U, Flor H, Hansson AC, 
Heim C, Hermann D, Kiebel S, et al. (2020) Addiction research consortium: losing and regaining control over drug intake (ReCoDe)from trajectories to mechanisms and interventions. Addict Biol 25: e12866.

Hikida T, Kimura K, Wada N, Funabiki K, Nakanishi S (2010) Distinct roles of synaptic transmission in direct and indirect striatal pathways to reward and aversive behavior. Neuron 66:896-907.

Hölter SM, Danysz W, Spanagel R (1996) Evidence for alcohol anticraving properties of memantine. Eur J Pharmacol 314:R1-R2.

Hölter SM, Danysz W, Spanagel R (2000) Novel uncompetitive Nmethyl-D-aspartate (NMDA)-receptor antagonist MRZ 2/579 suppresses ethanol intake in long-term ethanol-experienced rats and generalizes to ethanol cue in drug discrimination procedure. J Pharmacol Exp Ther 292:545-552.

Klenowski PM, Shariff MR, Belmer A, Fogarty MJ, Mu EW, Bellingham MC, Bartlett SE (2016) Prolonged consumption of sucrose in a binge-like manner, alters the morphology of medium spiny neurons in the nucleus accumbens shell. Front Behav Neurosci 10:54.

Kolik LG, Nadorova AV, Seredenin SB (2017) Non-competitive NMDA receptor antagonist hemantane reduces ethanol consumption in long-term alcohol experienced rats. Bull Exp Biol Med 164:152-157.

LaLumiere RT, Kalivas PW (2008) Glutamate release in the nucleus accumbens core is necessary for heroin seeking. J Neurosci 28:3170-3177.

Lobo MK, Nestler EJ (2011) The striatal balancing act in drug addiction: distinct roles of direct and indirect pathway medium spiny neurons. Front Neuroanat 5:41.

Lüscher C (2013) Drug-evoked synaptic plasticity causing addictive behavior. J Neurosci 33:17641-17646.

Lüscher C, Malenka RC (2011) Drug-evoked synaptic plasticity in addiction: from molecular changes to circuit remodeling. Neuron 69:650-663.

Ma T, Cheng Y, Roltsch Hellard E, Wang X, Lu J, Gao X, Huang CCY, Wei XY, Ji JY, Wang J (2018) Bidirectional and long-lasting control of alcohol-seeking behavior by corticostriatal LTP and LTD. Nat Neurosci 21:373-383.

Mameli M, Halbout B, Creton C, Engblom D, Parkitna JR, Spanagel R, Lüscher C (2009) Cocaine-evoked synaptic plasticity: persistence in the VTA triggers adaptations in the NAc. Nat Neurosci 12:1036-1041.

Niewoehner B, Single FN, Hvalby $\varnothing$, Jensen V, Meyer zum Alten Borgloh S, Seeburg PH, Rawlins JN, Sprengel R, Bannerman DM (2007) Impaired spatial working memory but spared spatial reference memory following functional loss of NMDA receptors in the dentate gyrus. Eur J Neurosci 25:837-846.

Parkitna JR, Engblom D, Schütz G (2009) Generation of Cre recombinase-expressing transgenic mice using bacterial artificial chromosomes. Methods Mol Biol 530:325-342.

Parkitna JR, Bilbao A, Rieker C, Engblom D, Piechota M, Nordheim A, Spanagel R, Schütz G (2010) Loss of the serum response factor in the dopamine system leads to hyperactivity. FASEB J 24:24272435 .
Pena-Bravo Jl, Penrod R, Reichel CM, Lavin A (2019) Methamphetamine self-administration elicits sex-related changes in postsynaptic glutamate transmission in the prefrontal cortex. eNeuro 6:ENEURO.0401-18.2018.

Pitchers KK, Schmid S, Di Sebastiano AR, Wang X, Laviolette SR, Lehman MN, Coolen LM (2012) Natural reward experience alters AMPA and NMDA receptor distribution and function in the nucleus accumbens. PLoS One 7:e34700.

Popik P, Kos T, Zhang Y, Bisaga A (2011) Memantine reduces consumption of highly palatable food in a rat model of binge eating. Amino Acids 40:477-485.

Sanchis-Segura C, Spanagel R (2006) Behavioural assessment of drug reinforcement and addictive features in rodents: an overview. Addict Biol 11:2-38.

Sanchis-Segura C, Borchardt T, Vengeliene V, Zghoul T, Bachteler D, Gass P, Sprengel R, Spanagel R (2006) Involvement of the AMPA receptor GluR-C subunit in alcohol-seeking behavior and relapse. J Neurosci 26:1231-1238.

Scofield MD, Heinsbroek JA, Gipson CD, Kupchik YM, Spencer S, Smith AC, Roberts-Wolfe D, Kalivas PW (2016) The nucleus accumbens: mechanisms of addiction across drug classes reflect the importance of glutamate homeostasis. Pharmacol Rev 68:816-871.

Soares-Cunha C, Coimbra B, Sousa N, Rodrigues AJ (2016) Reappraising striatal D1- and D2-neurons in reward and aversion. Neurosci Biobehav Rev 68:370-386.

Spanagel R (2017) Animal models of addiction. Dialogues Clin Neurosci 19:247-258.

Tukey DS, Ferreira JM, Antoine SO, D'amour JA, Ninan I, Cabeza de Vaca S, Incontro S, Wincott C, Horwitz JK, Hartner DT, Guarini CB, Khatri L, Goffer Y, Xu D, Titcombe RF, Khatri M, Marzan DS, Mahajan SS, Wang J, Froemke RC, et al. (2013) Sucrose ingestion induces rapid AMPA receptor trafficking. J Neurosci 33:61236132.

Vengeliene V, Bachteler D, Danysz W, Spanagel R (2005) The role of the NMDA receptor in alcohol relapse: a pharmacological mapping study using the alcohol deprivation effect. Neuropharmacology 48:822-829.

Vengeliene V, Bilbao A, Spanagel R (2014) The alcohol deprivation effect model for studying relapse behavior: a comparison between rats and mice. Alcohol 48:313-320.

Wei S, Hertle S, Spanagel R, Bilbao A (2021) Female mice are more prone to develop an addictive-like phenotype for sugar consumption. Sci Rep 11:7364.

Wiss DA, Avena N, Rada P (2018) Sugar addiction: from evolution to revolution. Front Psychiatry 9:545.

Zamanillo D, Sprengel R, Hvalby O, Jensen V, Burnashev N, Rozov A, Kaiser KM, Köster HJ, Borchardt T, Worley P, Lübke J, Frotscher M, Kelly PH, Sommer B, Andersen P, Seeburg PH, Sakmann B (1999) Importance of AMPA receptors for hippocampal synaptic plasticity but not for spatial learning. Science 284:1805-1811. 